\title{
POSSÍVEIS ARTICULAÇÕES DA FILOSOFIA COM A EDUCAÇÃO DO PENSAMENTO
}

\author{
Paulo Sérgio Dantas Vasconcelos ${ }^{1}$
}

RESUMO: Nossos estudos estão voltados à discussão de problemas gerados na práxis pedagógica do Ensinar Filosofia. Toda análise que envolve o ensino de filosofia, seja ele em qualquer nível, não pode desmerecer, antes de tudo, uma acurada atenção aos problemas peculiares referentes a essa atividade. Ensinar filosofia é um desafio permanente, que em sua dimensão prática articula-se com didáticas e metodologias as mais diversas sem, contudo, merecerem estas a atenção de grande parte dos docentes. Desse modo, a formação em filosofia em nossas instituições se constitui, em sua maioria, por esse divórcio com a educação, como se fosse possível à filosofia negligenciar a sua dimensão educativa ou mesmo o seu propósito de ensinar o homem a fazer-se homem enquanto pensa, reflete e dialoga politicamente como ser agente e transformador do real.

PAlAVRAS-CHAVE: Educação; Ensino; Filosofia; Práxis Pedagógica.

ABSTRACT: Our studies are focused on discussion of issues raised in the pedagogical praxis of Teaching Philosophy. Any 
analysis that involves the teaching of philosophy, be it at any level, can not disparage, above all, a careful attention to the peculiar problems related to this activity. Teaching philosophy is an ongoing challenge, which in its practical dimension is linked with teaching methodologies and the most diverse but without the attention they deserve a large part of teachers. Thus, training in philosophy in our institutions is mostly for that divorce education as if it were possible to philosophy neglect its educational dimension or even its purpose to teach a man to become a man while think, reflect and dialogue as being politically transforming agent and the real.

KEYWORDS: Education; Teaching; Philosophy; Educational Praxis. 


\section{INTRODUÇÃO}

Julgamos que o ensinar filosofia não nos permite, pela sua própria razão prática, prescindir do caráter pedagógico do qual essa ação se reveste. Compreendemos serem nossas reflexões sobre esse exercício indissociáveis daquilo que responde à essência do filosófico. Assim, não há problema em filosofia que não absorva na mesma proporção a questão da educação, uma vez que o problema/signo filosófico é o que nos "ensina a pensar” e, ensinando, promove nossa emancipação.

De certo modo essa compreensão da filosofia como educação do pensamento parece, antes de tudo, responder a uma vocação que acompanha sua prática desde os gregos e que tão-somente pretendemos aqui resgatá-la. Cremos que a paideia que estava no nascimento da filosofia e atravessa expressiva parte de sua história é ainda em nosso tempo o horizonte a que se destina todo o ensinar da filosofia e que, por sua vez, concede ao seu exercício uma multiplicidade de sentidos.

Filosofia como educação do pensamento não é para nós um confisco circunstancial com o qual possamos preencher lacunas entre conteúdos programáticos aplicados ou um dispositivo que venha satisfazer a ausência da "matéria" ensinada na escola ou ainda um recurso que procure responder tão-somente às exigências de adequação com as novíssimas propostas metodológicas, é sim uma atitude que nos diz que filosofia não se "dá" porque não se dá pensamento a ninguém; pensamento não se ensina como quem transmite o já pensado para outro que o retém. 
Filosofia como educação dopensamentoéantes a restituição do problemático à experiência filosófica e, consequentemente, a possibilidade de a filosofia fazer admirado, qual o escravo de Menon, aquele que pensa e se apropria de si mesmo, espantase por possuir aquilo que a escolarização do pensar trata de confiscar-lhe. Acreditamos que a pergunta/problema é que é primeiro no pensamento e não há quem a possa fazer por nós, pois se queremos educar nosso pensar, devemos deixálo encontrar-se com o problemático nas esquinas de nossas experimentações, propiciando o thauma inventivo que faz do ensinar um deixar aprender e do pensar um poetar.

Conceber a filosofia como uma prática educativa do homem é propor uma legítima educabilidade filosófica que desde a antiguidade já se manifesta no esforço socrático de realização da maiêutica, mas que, sobretudo, atualiza-se em todo o filosofar dialógico. Ou seja, toda atividade filosofante que se digne traz em sua essência o propósito de emancipação daquele que, educando seu pensar, educa-se e colabora sobremaneira para a educação de outrem.

Uma articulação entre filosofia e educação contribui para entender que o ensino de filosofia, muito mais que questão de ordem didática, impõe-se como problema de ordem filosófica e tão-somente dessa maneira deve ser tratado. Quando se faz filosofia do ensino de filosofia, devemos questionar: estamos ensinando filosofia antes mesmo de ter aprendido a pensar? Estamos afastando o ensino de filosofia daquilo que efetivamente lhe interessa: a experiência do pensamento livre?

Compreendemos, portanto, que se existe uma nítida distinção entre doutrinas e sistemas filosóficos por um lado 
e postura filosófica por outro, a simples aprendizagem de um conteúdo (História da Filosofia) não garante por parte do mestre a capacidade de filosofar. Para essa qualificação, cremos, é preciso a apropriação do filosofar, pois a ensinabilidade articula-se diretamente com esta numa relação de quase identidade. Assim, para ensinar filosofia, é preciso, sobretudo, atitude filosófica.

Aristóteles, em sua Ética (1094a), admite que toda arte (téchne) tem em mira um bem qualquer; assim, a atitude filosófica constitui-se como uma ação (pragma) poiética, fabricadora de outras ações. Ação que gera ações, atitude que cria atitudes, a práxis filosófica é poíesis enquanto fecunda mobilizações. Compreendida enquanto arte, a atitude filosófica não se reduz, entretanto, à mímesis de outras práxis na medida em que a experiência do pensar é, em sua natureza, irredutivelmente solitária, existencial. A ideia de uma suposta transferência de conteúdos filosóficos ou filosofemas acabados que possam capacitar o aluno em filosofia é a própria desconfiguração da filosofia. A atitude filosófica não é contemplação, status absoluto, enteléquia, forma pura, mas, sim, transformação, perturbação, privação, possibilidade, dýnamis.

Castoriadis (1987) afirma ser a educação uma atividade prático-poética, pois nela a autonomia faz-se simultaneamente meio, isto é, a razão de ser própria da atividade, e fim, o possível produto a ser visado. Por essa interpretação, uma educação filosófica reúne o que a classificação aristotélica, em seus princípios, separa: a práxis da poíesis. O filosofar, enquanto exercício de pensamento, é também exercício dessa autonomia vibrante que atua concomitantemente tanto no 
favorecimento do sujeito agente quanto no outro (no caso o aluno) que, no próprio kínesis-dialético, move-se movendo.

Essa fenomenologia da educação filosófica propõe necessariamente a ruptura da dicotomia moderna sujeitoobjeto posto que a manutenção das posições professoraluno deve ser abolida na própria práxis que, sendo dialógica, alimenta-se dessa vertiginosa reconfiguração de status pedagógico. Desse modo, a prática filosófica é atualidade de morfologias pedagógicas instáveis que redistribuem o espaço-tempo didático. Não é da prática filosófica o sombreamento do pensar, no qual, por um lado o aluno aliena-se no já pensado; por outro, o mestre aliena-se no seu próprio já pensado. A ideia kantiana de autonomia é assumida como pressuposto deste pensar desobediente, inconformado, selvagem e que se arrisca nos abismos de si mesmo. Amante do erro muito mais que da evidência conduz a filosofia às arenas das erísticas, ao agôn das discussões.

A dissolução da dicotomia sujeito-objeto não implica por sua vez o desaparecimento da tensão dialética: compreender a filosofia como ato de filosofar requer a instauração do conflito motivador do pensar. A imagem do pensador ausente, ermitão cartesiano enclausurado num cogito, desvanece diante do aparecimento do Outro, antítese. O filósofo é esse que, filosofando, lança-se definitivamente no mundo por intermédio da consciência, dos afetos, do corpo. A experiência filosófica é, em sua natureza dialógica, a afirmação desse comprometimento solúvel de uma razão 
apaixonada que se realiza tão-somente nesse construirdesconstruir, nesse rosto de faces contrárias que o diálogo desenha.

A educação filosófica convida, portanto, a uma aproximação de experiências de pensamento fecundada no diálogo. Signo dessa abertura, o pensamento filosófico é desejo (Eros) de conhecer, mas, sobretudo pertença do mundo humano compartilhado. O Eu que se funda na trama dialógica não é o eu do pensamento puro, mas sim o eu de Montaigne (1987), que é também metade do outro. A atitude filosófica do professor de filosofia é poíesis quando deseja a atitude filosófica do aluno, convida-o a atualização de suas próprias experiências de pensamento. O Eros filosófico é também elos que amarram ambos na teia do desejo. O Eros filosófico, enquanto procura, realiza-se nessa busca incessante que faz do amor à sabedoria o próprio desejo de não a encontrar.

Situado neste mundo, o filósofo vive a experiência do pensamento e por ela opera por meio de uma pedagogia dialógica a desconstrução dele próprio. É que a experiência de pensamento constitui-se como um reaprendizado, uma desconstrução vertiginosa. Sendo ela mesma o inter-esse do filosofar, não se compromete portanto com metas, propósitos, finalidades, mas sim com o próprio caminhar. O espanto filosófico não apenas inaugura, mas permanece realimentando toda a experiência. E assim o filosofar, não condicionado pelas chegadas, vai inventando caminhos, criando e apagando pegadas verdadeiramente pedagógicas.

Entendida a experiência do pensamento como uma prática do filósofo, a filosofia é também exercício de 
uma phronesis, isto é, uma racionalidade que nos permite conhecer e pensar o mundo dentro da experiência, da vida, e não em nível de um pensamento puro, abstrato. A filosofia, se vista como substância, coisa, pode ser ensinada por transmissão de conteúdo, porém se tomada enquanto filosofar, verbo, será sempre construção, fazer, fabricar. Desse modo, a ação filosófica pretende ser práxis, exercício de pensamento.

\section{EDUCAÇÃO FILOSÓFICA E EDUCAÇÃO DO PENSAMENTO}

A educação filosófica requer em sua dimensão práxis esse constante movimento do espírito, essa atividade incessante em que ensino e aprendizagem encontram-se. E é somente dentro dessa dinâmica que se entende a elaboração dos mecanismos do exercício poético, construtivo.

Nessa perspectiva, parece inevitável a pergunta sobre o sentido de filosofia que condiciona o próprio ensino da filosofia. Ou seja, não é possível ensinar filosofia sem efetivamente estarmos comprometidos com uma ideia ou mesmo uma finalidade desse ensino. Em síntese, o modo como entendemos ou valoramos a filosofia deve condicionar o seu ensino.

Assumir a filosofia como educação é entendê-la como resultado de um exercício de pensamento não-submisso. Pensamento que inaugura a própria atualidade, que diz o ser no presente. Desse modo, a história da filosofia pode se configurar como um poder negativo da própria filosofia e mesmo dentro do pensamento, um saber coercitivo. Não 
há como conciliar atitude filosófica do professor que, ao ensinar filosofia, constitui em sua práxis uma provocação de atitudes no aluno com a postura do professor que Deleuze chama "plagiador". O plagiador, ao submeter-se à autoridade de um Platão, Descartes ou Kant, submete por sua vez o aluno à repetição, tiraniza o seu pensar, condena a Filosofia à reprodução exaustiva da analítica de textos.

As consequências políticas desse pensar submisso devem ser também consideradas: quando submeto à reprodução uma disciplina que se vangloria de ser crítica, reitero a conservação da filosofia nos cânones, estimo unicamente as questões dos filósofos tradicionais e condeno por sua vez a filosofia a um pensamento descontextualizado e, consequentemente, despolitizado. Enquanto exercício dialético de pensamento, a filosofia, desde suas origens, constitui-se como ação política, pois requer sua inscrição num universo demasiadamente humano, onde os problemas discutidos são extraídos das próprias experiências do pensar e esse pensar está necessariamente prenhe de valores. Ou seja, não há filosofia que, sendo atividade, não esteja comprometida com o presente. Portanto, a sala de aula é um acontecimento, um fato, um organismo vivo, e será sempre importante a atualidade do pensar, que, por sua vez, torna também atualizada nossa existência.

$\mathrm{Na}$ dialética voltamos ao princípio: Sócrates, antes que qualquer outro, fez filosofia, não a reduziu a um solilóquio da razão. "Importa-me aqui o Sócrates vivo, que não ensinava filosofia, mas, filosofando, fazia filosofia" (LANGÓN, 2003, p. 90). Fez filosofia quando dialogou, quando viu nos seus interlocutores a possibilidade de tornar sua reflexão (não 
reflexão "sobre" as coisas) parte de um reflexo provindo do pensar do outro. Guillermo Obiols (2002, p. 109), de certa forma, compartilha dessa ideia quando afirma que em Sócrates "não se pode distinguir o ato de filosofar do ato de ensinar nem o de ensinar do de filosofar [...]". O diálogo socrático, portanto, nos faz entender o quanto nosso pensar "espelha" a alteridade e de que modo a aventura dialógica nos vai conduzindo por caminhos que previamente jamais poderíamos desenhar. O filosofar dialógico expressa, sobretudo, uma racionalidade compartilhada, uma jornada que se inicia de um ponto (tese), mas que contém em sua trajetória a possibilidade de sua própria negação (antítese). Razão compartilhada, o diálogo valoriza o indivíduo em sua singularidade própria, mas uma singularidade que só emerge em relação com o outro. Enfim, no diálogo, caminhamos e falamos conosco e com os outros. Caminho esse em que a chegada (síntese) é também desejo de uma nova partida. Só o filosofar dialógico revitaliza o sentido radical da pedagogia (agogé) enquanto reconstitui a aliança desta com a filosofia. O diálogo fez surgir a filosofia como discussão e, dessa forma, reaproximá-la do seu primado pedagógico é também reconduzi-la a sua mais autêntica expressão.

Quando tratamos de ensino, falamos consequentemente de uma prática que requer uma ação transformadora do aluno, mas, antes de tudo, transformadora do professor. Educação é condução simultânea de ambos, pois nesta atividade está contido o desafio que se coloca em tudo o que se diz fascinante. Se educação é algo fascinante, é porque é desejo de descoberta, ato que preserva tão-somente a fecunda vontade de mudar. 
No caso do ensino de filosofia, a conservação da postura professor-conteúdo parece ser ainda mais grave: parece inconcebível que se possa construir uma aula de filosofia sem efetivamente filosofar. A palavra, o texto filosófico, não deve escravizar o espírito, ordenando-o dentro do cânone da tradição. Ler um Descartes é abertura para infinitas possibilidades cartesianas, é encontro com o encanto do texto. O professor que transmite filosofia nega à própria filosofia o direito de ser justamente aquilo que em sua natureza ela é: admiração.

O ensino de filosofia, quando se propõe filosófico, não deve submeter a atividade de pensar à autoridade de um texto, condicionando esse pensar a uma regulamentação. Desse modo, a referência prévia à verdade antecipa-se ao próprio exercício do filosofar, conduzindo-o à supressão do inventivo, do artístico, do maravilhamento da descoberta. Se a filosofia é produção de conceito, produção de pensamento, disciplinar a racionalidade filosófica por intermédio desse mecanismo é comprometê-la definitivamente nos limites conformadores de verdades historicamente constituídas. Nesse caso, a história da filosofia contribuiria para o trabalho antifilosófico do pensamento, domesticando-o, conduzindo-o a uma prática inócua de legitimação do já pensado.

O que emerge da "filosofia prática" é o pensar criativo, que, não subordinado à razão disciplinar, constitui em sua práxis as feições de sua singularidade. O fazer filosófico não se prende às redes de enunciados que, de antemão, estabelecem as possibilidades do pensar, não se submete à ordem reificadora da tradição, não se acovarda frente os 
paradigmas estandartizadores. O filosofar, quando dialético, desautoriza em sua vigência os regimes epistemológicos de construção de verdades estruturadas na ordem do discurso autorizado e inaugura o interessante pensar posto por uma ontologia movente, transgressora, na qual o problematizado não se confina no interior de um sistema circular, de uma estrutura autoconfirmadora.

Quando se afirma a filosofia como uma atividade do pensamento inventivo, criador, não se quer com isso compreender como desnecessário o uso da sua História, mas justificar a prática do diálogo com seus autores. Aristóteles, Hume, Kant, Husserl, não devem pensar por nós, mas pensar conosco. Ou seja, a história da filosofia não deve prestar um desserviço à própria filosofia, constituindose como instrumento único de sua validação. A liberdade de pensamento, primado de qualquer filosofia merecedora desse nome, efetivamente passa pelo método-caminho dialogal e por ele também se restitui o papel social do filósofo quando do compartilhamento com outros dos problemas discutidos. Portanto, ao dialogar com a sua História, a um só tempo fazemos filosofia, e a reconduzimos as suas origens fecundantes. Em Diálogos, Deleuze e Parnet dizem que

[...] a História da Filosofia sempre foi um agente de poder na filosofia, e mesmo no pensamento. Ela desempenhou o papel de repressor: como você quer pensar sem ter lido Platão, Descartes, Kant e Heidegger, e o livro de fulano ou sicrano sobre eles (DELEUZE; PARNET, 1998, p. 21). 
Para os pensadores franceses, acima citados, a história da filosofia tiraniza o pensar, determinando tanto o modo quanto os requisitos do que se pode pensar. Nesse caso, a história da filosofia condiciona até mesmo o percurso do pensar, direcionando-o às metas previamente estabelecidas e configura-se unicamente como reprodução mimética das ideias dos grandes filósofos. Assim, a aula de filosofia não teria outro fim senão legitimar respeitosamente a tradição, abdicando por sua vez do exercício do livre pensar.

Se a filosofia é entendida como educação do pensar, essa educação não pode pretender-se formação do pensamento, pois a razão filosófica é antes de tudo aberta, ela é transformação do espírito. Esse filosofar manifesta-se no aprendizado do seu próprio exercício, que é tanto meio quanto fim. Ou seja, a razão filosófica tendo sua ontologia movente, caminhante, não-domesticada, subverte a todo momento os regimes de produção da verdade, restituindo o seu poder criativo, inaugural. Assim, não havendo formação que restrinja a liberdade do pensar, todo problema filosófico supõe a negação de qualquer limite e, muito mais que buscar atender às exigências das capacidades exegéticas conformadoras, às habilidades "técnicas" da boa leitura do texto, cabe à autêntica filosofia justificar seu rigor na observância do direito a sua própria liberdade.

É essa atividade liberta das imposições dos sistemas de produção de verdades reificadas que faz Sthéfhane Douaillier (2003) compreender que o ensino de filosofia é uma espécie de "poder de começo", ou seja, todo o filosofar inaugura em sua manifestação criadora o desejo de re-começar a filosofia à sua maneira. Desta forma, o itinerário tomado pelo 
filosofar é, em sua magnitude, a descolonização do pensar por meio da criatividade, da re-invenção de si mesmo. Todo o filosofar traz em seu bojo o poder de recriação da filosofia, isto é, inaugura um percurso novo a ser iniciado do lugar de cada experiência de pensamento, na singularidade de cada vontade particular, na predileção de cada roteiro a ser tomado. Portanto, por não haver um único "caminho" a ser seguido, a aventura filosófica é, acima de tudo, livre; é desobediência fecundante de cada "espanto" original.

O "andarilho" filósofo é, como Nietzsche afirmou, aquele que escolhe o "insólito, assombroso, difícil, divino" (1987, p. 17-18), e dessa forma não pode temer os seus possíveis descaminhos. Como todo ato criador, o pensamento é atividade que deve ser saboreada (aqui é pertinente lembrar a aproximação das expressões latinas sapere e sapore!) em seu próprio momento de ação, na identificação do pensar que se constitui como apropriação do exercício, isto é, apropriação do que chamamos arte de pensar.

O filosofar não pode perder em sua dimensão pedagógica esse sentido gustativo do aprender que o faz experiência com "refinamento de gosto"; o aprender-ensinar filosofia deve ser contaminado por esse inter-esse pelo agradável que o faz ser, além de uma atividade necessária, uma "ginástica" saborosa do espírito. É que o necessário do filosofar revelase primeiramente no prazer do pensar desejoso, na conquista da autonomia, na posse da consciência crítica que respalda a própria noção de identidade, e esse necessário para o eu que pensa irradia no outro o gosto de aprender. Assim, o filosofar faz-se útil, agradável e mais soberanamente importante. 
Desse modo, dentro de uma práxis pedagógica do professor de filosofia, a questão fundamental que inaugura privilegiadamente a discussão está muito mais localizada numa educação do filosofar que numa filosofia da educação. Isso porque o filosofar é autoconhecimento, é busca de si mesmo, é desvelamento. Se há uma verdade em Filosofia, ela está nesse encontro consigo que se projeta no outro. $\mathrm{O}$ filósofo, ao educar seu pensamento, educa a si mesmo e, nesse sentido, requer em sua atividade contaminadora o desejo socrático do "cuidar da alma". Esse sentido terapêutico é o mesmo que faz Nietzsche definir o filósofo como "o médico da civilização". Neste sentido, filosofar significa interpretar e diagnosticar os "males da civilização", encontrar remédios para curá-la ou então envenenar aquilo que a destrói.

Acrescenta-se ainda que o vínculo da filosofia com a educação faz-se também pela dimensão "práxis" que envolve ambas. Uma educação da filosofia recoloca nesta última o seu propósito moral, político, pedagógico; resgata o seu valor humanístico na atenção aos problemas existenciais, reintegra o filósofo no social, enfim, embeleza a racionalidade, tornando-a viva, efetiva. "Aprender a pensar", como Nietzsche diz, não é subjugar o pensamento às verdades cristalizadas.

[...] a história erudita do passado jamais foi o afazer de um verdadeiro filósofo [...] um professor de filosofia, quando está ocupado com um trabalho desse gênero, deve se contentar com que se diga dele, no melhor dos casos: "É um bom filólogo [...] um bom linguista, um bom historiador" - mas nunca: "É um filósofo". (NIETZSCHE, 2003, p. 212) 
Portanto, faz-se necessário compreender a filosofia como diagnóstico do seu tempo, grávida do presente. Devemos, pois, educar a filosofia na escuta das suas reais questões, fazê-la atual, pertinente. A filosofia deve permanecer em contato com a fonte dos problemas que requerem ser estudados e resolvidos, pois só assim consegue responder a sua maior finalidade.

Assim como a educação, em seu fim pedagógico, a filosofia é, na concepção de Heidegger, um caminho sobre o qual estamos a caminho (Cf. HEIDEGGER, 1989a, p. 14). Mas é caminho-chão, não renuncia a realidade, não abandona a existência, a inerência com o mundo e quanto mais se faz dialética tanto mais se afeiçoa ao inacabamento mesmo que almeje a totalidade. Posta em diálogo, a filosofia é expressão de infinitas perspectivas que, no interior do diálogo, se interagem como interlocutores iguais. Assim, cada perspectiva entra no diálogo com a possibilidade de ser alterada; isso quer dizer que se ampliam ainda mais os caminhos a ser tomados pela razão dialética. Ou seja, caminhos sempre se abrem no diálogo. Bréhier diz que "tudo que é fechado em Filosofia, tudo que se dá como solução e sistema acabado [...], não tem valor filosófico" (BRÉHIER apud COÊLHO, p. 41). Seu caminhar é expressão de um projeto permanentemente iniciado, vindo daí seu viço, sua novidade. O filosofar é atividade que ama não o instituído, mas o instituinte, que se rejuvenesce a cada momentodialógico, que avança na temporalidade da discussão, da dúvida, da crise, da contestação e, por esse movimento transgressor, postula sua dimensão educativa. 
O mais breve retorno às suas origens favorece também a compreensão da dimensão política que envolve a articulação entre filosofia e educação: filosofia e paideia (ação de educar) reúnem-se na edificação do espírito Ático. Filosofia e educabilidade política expressam o nexo de ligação dos problemas filosóficos com o existencial. Sendo a vida humana uma con-vivência, todo pensar parece participar de um tempo, uma língua, uma cultura, sem, contudo, pertencer inteiramente a nenhum deles. Se em seus primórdios a filosofia, educação e política constituíram conjuntamente o homem, é porque a concepção deste não poderia prescindir desta unidade. O ideal da arete, que fazia a alma assemelharse ao divino, tinha na educação o seu caminho e na política o seu fim. Portanto, esse status político deve permanecer sempre como horizonte de qualquer educação filosófica que pretenda responder às aspirações do homem na posse de sua soberania, na conquista de sua cidadania.

Filha da cidade, como diz Vernant (1984), à polis deve retornar a filosofia. Esse enraizamento citadino, muitas vezes esquecido, dá à experiência filosófica o seu comprometimento ético, restituindo-lhe a sua herança primordial. Se há um tempo para a filosofia enquanto atividade do espírito livre, esse tempo é o presente.

Habituar a filosofia a tratar de "casos-pensamentos" é deixar que o cotidiano se torne 'caso' que gera o pensar; as provocações motivadoras do filosofar são extraídas não somente do extra-ordinário, mas do lugar da experiência de cada um. O "poder de começo" conferido ao ensino de filosofia constitui-se pelo exercício do pensamento livre que inaugura todo momento uma superação do próprio 
mestre. Em outros termos, a jornada de cada pensador faz-se justamente quando ele "mata" seu mestre e constrói seu próprio roteiro intelectual. Portanto, este recomeço parece dizer justamente de uma necessidade constante de fazer do pensamento um processo ligado à experiência de cada um. O contexto, de onde brota o problema, pode suscitar uma questão filosófica. Desse modo, o pensamento permanece ligado às sensibilizações do dia a dia e, de alguma forma, comprometido com problemas vividos. Nesse sentido, é possível falar de uma razão sensível, isto é, de um pensamento conectado com o presente, contaminado de afetividade que não passa ao largo da vida, não é sobre as coisas, mas, fundamentalmente, na coisa. Portanto, se por um lado, essa ligação com o presente faz do ensino de filosofia uma prática política, vê-lo como atualização do espírito criativo, sensibilizado, é considerá-lo também como atividade poética.

Destarte, essa imanência do pensamento às questões da vida, comprometido com as coisas do mundo, destina o filosofar ao sentido ético dessa atividade. Éque, enquanto trata de problemas da existência, a filosofia parece corresponder ao propósito maior de sua prática. Atendendo às exigências de sua temporalidade, o filosofar não deve abandonar as questões do homem e, mais que isso, responder à pergunta: o que pode a filosofia fazer pelo homem neste mundo?

Qualquer resposta dada a essa questão abissal necessariamente remete a experiência filosófica às dimensões ética e pedagógica, pois a colaboração filosófica, neste caso, vincula-se absolutamente com o problema da formação humanística dada pela filosofia. Uma educação filosófica é sempre constituída pelo desejo de superação e/ ou transformação do humano e assim, enquanto as ciências 
procuram dizer como a vida é - vida psíquica, social, política, econômica, etc. -, não prescrevem uma conduta moral, não dizem como devemos conduzir nossas vidas. Por outro lado, quando o filosofar se liga à vida, vê-se atravessado por um sentido de preocupação existencial que procura permanentemente responder aos interesses de uma vida que valha a pena.

Contudo, a valoração da vida é uma construção, uma elaboração, um esforço de aprendizagem; é consequência de uma paideia. Esse processo de formação é inicialmente um cuidar de si, pois supõe uma educação moral elaborada no âmbito da experiência, da vivência subjetiva. Esse sujeito ético, enquanto indivíduo submetido aos valores, às significações da vida, fundamenta sua prática (no caso em questão, o ensino) como responsabilidade consigo mesmo, como privilégio de sua autenticidade. É que quando fazemos filosofia extraindo os problemas da carnalidade do real, não podemos abandonar esse compromisso com a vida, com essa pessoa que somos, com nossos sentidos, sentimentos, sensações. Portanto, o ensino de filosofia, quando prioriza a questão da significação da vida humana, privilegia, sobretudo, o cuidado que o professor tem com sua própria vida e, por extensão, com a vida do outro.

Todo ensino de filosofia parece mostrar em sua prática um modo de dizer como viver a vida, pois, se o filosofar não se submete ao discurso ideológico, à tirania da tradição, às crenças e preconceitos, o filosofar é livre, e sob o signo dessa liberdade se expressa o valor de uma prática de ensino que é ela mesma ensino de uma prática, isto é, o filosofar verdadeiramente ensina a filosofar. Esse talvez seja o grande equívoco do professor: julgar que bem transmite conteúdos quando, na verdade, comunica muito mais atitudes. 


\section{CONSIDERAÇÕES FINAIS}

O melhor desdobramento dessas questões requer que façamos primeiramente algumas distinções, a fim de melhor compreendê-las: quando se fala em ensino de filosofia como exercício de pensamento que é expressão de uma vida filosófica, é preciso distingui-lo do ensino de filosofia que pretende ser única e exclusivamente exegese de textos. Essa tradição academicista parece ter feito Wittgenstein, já no seu tempo de professor de Cambridge, manifestar a dificuldade de "ensinar filosofia honestamente". Quando o ensinar filosofia exprime "significação da existência", ele se compromete intimamente com o ético porque não abandona em nenhum momento as motivações morais, o alimento da vida. O que se identifica nas palavras de Wittgenstein é, sobretudo, a dificuldade de ensinar filosofia quando esta não se reduz à prática narcisista de transmissão do conteúdo histórico da filosofia, ao "tecnicismo" da leitura profissional do texto filosófico ou mesmo ao propósito mesquinho de reduzir a filosofia a uma hermenêutica vazia. O dilema do autor do Tractatus coloca-se a partir da compreensão da exigência ética incondicional que envolve a filosofia e as dificuldades próprias de ensiná-la. "Nós sentimos que, mesmo quando todas as questões científicas possíveis fossem resolvidas, nossos problemas de vida não seriam sequer tocados". (WITTGENSTEIN apud PRADO JR., 2008, p. 66). É que, se por um lado essa exigência motiva a prática do ensino de filosofia, por outro, parecem ser os problemas éticos irredutíveis à linguagem cognitiva e significante e, portanto, inexprimíveis. Em outras palavras, o sentido ético, por se achar fora do mundo, não é dizível, não pode ser ciência. Por se tratar de valor, "ele deve se achar fora 
de todo acontecimento e de todo ser-assim" (TRACTATUS, 6:41 apud PRADO JR. p. 66). Essas palavras nos remetem de súbito à constatação de um paradoxo: o que é ético deve ser ensinado; entretanto, não pode ser ensinado.

Esse paradoxo impõe um valoroso desafio ao professor de filosofia na medida em que emergem dele questões fundamentais como: qual a razão do ensino da filosofia? Qual o interesse real da filosofia na vida das pessoas? Por que deveria ensinar filosofia? Respostas a essas questões irão requerer especial atenção, pois elas inevitavelmente condicionam a prática do ensino de filosofia.

Os problemas levantados por Wittgenstein referentes ao ensino de filosofia na faculdade inglesa de sua época parecem hoje muito mais importantes de serem tratados. Então, não se pode desconsiderar que o fundamento maior de uma atividade profissional, seja ela qual for, é o ético. Ou seja, quando damos sentido às nossas práticas é que visamos finalidades, metas, e, dessa forma, comprometemos toda a humanidade por nossas escolhas. Assim, ensinar filosofia não é filosofar alhures, mas, sim, no mundo; é dialogar consigo e com o outro, é comunicar sentimentos, hesitações, entusiasmos, desgostos, enfim, compartilhar vidas.

Recoloquemos a questão em outros termos: se ensinar filosofia não é reduzi-la a resoluções de algumas questões técnicas, é porque a filosofia não pode caracterizar-se tão-somente como uma prática "capaz de se exprimir com alguma plausibilidade certas questões de lógica abstrusas, etc." (WITTGENSTEIN apud PRADO Jr., 2008) Logo, não há como descolar a filosofia e o seu ensino dos problemas da vida e por essa mesma razão devemos aceitar o dilema de Wittgenstein como o desafio de todo aquele que com a filosofia trabalha. 
Mas o que se extrai dessas dificuldades apresentadas é que, primeiramente, não podemos negligenciá-las sob pena de estarmos em nosso exercício de professores de filosofia fazendo a "antifilosofia", isto é, indo de encontro aos próprios anseios da verdadeira filosofia e, do mesmo modo, é preciso entender que só podemos verdadeiramente enfrentar esses desafios na arena das nossas atividades. Ou seja, quando ensinamos filosofia, não como um conteúdo sedimentado, mas como uma atividade do espírito livre que vai dialeticamente construindo conceitos, quando a compreendemos como um permanente movimento de ideias em processo de construção e não como um corpo de doutrinas, sabemos que estamos mais próximos daquilo que a máxima kantiana nos diz, a saber, não se pode ensinar filosofia, mas podemos ensinar a filosofar.

Nasce daí um "saboroso" desafio que se apresenta a cada momento que escolhemos ensinar filosofia sem ao menos termos ainda respondido o que ela é. Esse radioso problema não tem resposta definitiva, pois não há modo mais autêntico de dizer o que é filosofia senão o próprio fazer filosófico e essa procura amorosa (eis o sentido da erótica platônica!) alimenta a práxis filosófica pelos caminhos sinuosos do diálogo. O que há de filosófico no ensino de filosofia é, sobretudo, o sentido que ilumina toda a prática. Em síntese, a resposta que damos à questão: "Para que serve a filosofia?", damos necessariamente em nossa práxis mesmo quando a negligenciamos, pois não há conduta humana que não contenha em seu bojo um modo de ensinar a fazer, e nessa atividade ensinante a filosofia vai dizendo todo momento o que ela é. A pergunta "O que é filosofia?" é filosófica justamente por encontrar sua melhor resposta na própria atitude filosofante. Os caminhos do filosofar dialético 
constroem a filosofia como uma investigação prenhe de riscos, percursos de percalços, dúvidas, mas, sobretudo, inventividade, isso porque o filosofar é sempre possibilidade de reinvenção do mundo, vontade de princípio. E essa inspiração atuante do pensamento faz do ensino de filosofia uma atividade artística; no sentido de arte como ideia do que pode vir-a-ser, arte como projeção fecundante do homem no mundo, arte como renascimento do ser, invenção da vida.

\section{NOTA}

${ }^{1}$ Doutor em Educação (UFBA). Professor de Filosofia da Universidade do Estado da Bahia (UNEB). Endereço eletrônico: paulo_filo@hotmail.com.

\section{REFERÊNCIAS}

ARISTÓTELES. Ética. São Paulo: Abril Cultural, 1987.

CASTORIADIS, C. As Encruzilhadas do Labirinto I. Rio de Janeiro: Paz e Terra, 1987.

COÊLHO, I. M. Filosofia e Educação. In: PEIXOTO, J. A (Org.). Filosofia, Educação e Cidadania. São Paulo: Alínea, 2001.

DELEUZE, G.; PARNET, C. Diálogos. Tradução Eloisa Araújo Ribeiro. São Paulo: Ed. Escuta, 1998.

DOUAILLIER, S. A filosofia que começa: desafios para o ensino da filosofia no próximo milênio. In: GALLO, S; CORNELLI, 
G.; DANELON, M. (Org.). Filosofia do Ensino de Filosofia. Petrópolis, RJ: Vozes, 2003.

HEIDEGGER, M. Que é Isto - A Filosofia? Tradução Ernildo Stein. São Paulo: Nova Cultural, 1989a. (Os Pensadores).

LANGÓN, M. Filosofia do Ensino de Filosofia. In: GALLO, S.; CORNELLI, G.; DANELON, M. (Org.). Filosofia do Ensino de Filosofia. Petrópolis, RJ: Vozes, 2003.

MONTAIGNE, M. Ensaios. São Paulo: Abril Cultural, 1987.

NIETZSCHE, F. A Filosofia na Época Trágica dos Gregos. São Paulo: Abril Cultural, 1987.

NIETZSCHE, F. Consideração Intempestiva: Schopenhauer como educador. In: Escritos sobre Educação. Tradução, apresentação e notas de Noéli Correia de Melo Sobrinho. Rio de Janeiro: Ed. PUC-Rio; São Paulo: Loyola, 2003.

OBIOLS, G. Uma Introdução ao Ensino da Filosofia. Tradução Sílvio Gallo. Ijuí: Ed. Unijuí, 2002.

PRADO Jr., P. Aprender a Viver - Wittgenstein e o "não-curso" de Filosofia. In: BORBA, S.; KOHAN, W. (Org.). Filosofia, Aprendizagem, Experiência. Belo Horizonte: Autêntica Editora, 2008.

VERNANT, J. P. As Origens do Pensamento Grego. Rio de Janeiro: Bertrand Brasil, 1984. 